\title{
Aspectos morales y jurídicos de la deuda externa
}

César Delgado Barreto

\section{Introducción}

Nunca la historia de la sociedad internacional ha sido tan interdependiente. Por ello, las relaciones económicas, políticas, estratégicas, militares y humanitarias hoy son parte de una misma realidad. La interdependencia del mundo actual está también en la base de una preocupación ética y universal para proteger los derechos humanos.

Desaparecido el antagonismo Este-Oeste que antes dividía la humanidad, queda la oposición Norte-Sur. La real división entre los Estados contemporáneos es la que separa a los países más ricos de los países pobres. Casi un cuarto de la población mundial (1 300 millones de personas) vive en la miseria absoluta, mientras que un quinto de los 5600 millones de habitantes del planeta goza del $85 \%$ de las riquezas. También en el interior de los países del tercer mundo existen diferencias abismales entre una minoría que detenta el poder político y económico y las mayorías famélicas. El mundo nunca podrá disfrutar de la paz mientras subsista esta inhumana e injusta distribución de la riqueza que atenta contra los más elementales derechos humanos.

Por eso, resulta incomprensible que cuando se tratan las cuestiones relativas a los derechos humanos se intente segmentar la realidad internacional hablando de la "pobreza" (por ejemplo, en la Comisión de Derechos Humanos de las Naciones Unidas o en la Cumbre Social de Copenhague), sin mencionar el desarrollo, ni los efectos de las políticas de ajuste económico en el goce de los derechos humanos; como también intentar cautelar los derechos humanos referidos a las libertades fundamentales y los derechos civiles y políticos, promoviendo su investigación allí donde se violan, pero al mismo tiempo negándose a decidir lo mismo en relación a las violaciones de los derechos humanos que atañen más a la existencia misma del hombre, como pueden ser el derecho a la 
alimentación, a la vivienda, a la salud, a la educación, en una palabra, el derecho al desarrollo de las personas y de los pueblos.

O intentar, por otro lado, con la misma miopía, una desvinculación entre las políticas financieras y económicas internacionales, que son decididas por los países industrializados, con sus efectos negativos en términos de incidir directa o indirectamente en la violación de los derechos humanos de pueblos enteros. Resulta también ajeno a toda lógica y ética continuar el silencio frente al círculo vicioso de la pobreza, la presión por el cambio social, la insurrección y la represión estatal.

La protección de los derechos humanos es un patrimonio de toda la humanidad, pero para ser efectiva no puede incurrir en tratamientos selectivos en los cuales las causas estructurales y las derivadas de un injusto sistema económico mundial sean ignoradas.

No es ético, por ello, mantener una actitud ambivalente de preocupación por los derechos humanos con enfoques selectivos, a la vez que una negación sistemática, por ejemplo, a resolver el problema de la deuda externa. La universalidad en la protección de los derechos humanos no puede aceptar fronteras temáticas ni privilegiar unos derechos sobre otros. Se debe terminar con la segmentación de la realidad internacional y asumir con responsabilidad la vinculación que existe entre la estructura económica internacional, las decisiones del sistema financiero internacional -que ahondan la pobreza-, las políticas de intervención -que inhiben el derecho de los pueblos-y el goce efectivo y pleno de todos los derechos humanos.

Teniendo en cuenta la estrecha relación existente entre la deuda externa y el efectivo respeto de los derechos económicos, sociales y culturales, la delegación peruana al 45 período de sesiones de la Comisión de Derechos Humanos, reunida en Ginebra en febrero de 1989 -y que tuve el honor de presidir-, conjuntamente con las delegaciones de $\mathrm{Co}-$ lombia, Cuba, México, Panamá y Venezuela, presentamos el siguiente proyecto de resolución: "Considerando que el progreso social y el desarrollo económico en todos los países constituye un factor fundamental en la promoción integral de los derechos humanos y las libertades fundamentales; decide inscribir en el programa de su 46 período de sesiones, dentro del tema del programa titulado "Los problemas relacionados con el derecho a disfrutar de un nivel de vida adecuado, el derecho al desarrollo", un inciso específico sobre: "La deuda externa, las políticas de ajuste económico y sus consecuencias en el goce efectivo de los derechos humanos, especialmente en la aplicación de la Declaración sobre el Derecho al Desarrollo"”.

El proyecto de resolución fue aprobado después de un arduo debate, a pesar de la oposición de los países desarrollados capitalistas, que ar- 
güían que el foro para debatir el problema de la deuda no era la Comisión de Derechos Humanos, sino los organismos especializados económicos, financieros y monetarios de las Naciones Unidas. Los países en vías de desarrollo sostuvimos que el problema de la deuda era ante todo un problema ético, jurídico y político, cuyo pago afectaba el gozo efectivo de los derechos económicos, sociales y culturales, y que mientras no existiese una conciencia lúcida de la gravedad del problema que afecta la subsistencia de millones de seres humanos, así como la voluntad política de afrontarlo, los enfoques exclusivamente financieros y monetarios sólo iban a contribuir a su agravamiento.

No es posible que nos preocupemos, por ejemplo, por el derecho a la salud, si no condenamos y revertimos condiciones que se imponen para otorgar financiamiento a los países en desarrollo, y que consisten precisamente en disminuir la capacidad del Estado y la sociedad para la atención médica de la población. No es posible limitarse sólo a cautelar los derechos humanos que la violencia coyuntural destroza a diario. Es necesario evitar que la violencia surja, y esto sólo se podrá hacerlo eliminando las condiciones objetivas, la violencia estructural que producen la pobreza, la marginalidad y la opresión.

Por ello denunciamos las modalidades de ajuste que está utilizando el sistema financiero internacional y que está provocando, en una relación causa-efecto, violaciones de los derechos económicos, sociales y culturales, que, indirectamente, son la causa de las violaciones de los derechos civiles y las libertades fundamentales al fomentar la violencia social, la ruptura del orden jurídico y, en muchos casos, la insurgencia y la represión estatal.

En esta interdependencia entre subdesarrollo, injusto sistema económico internacional y vigencia de los derechos humanos, resulta injusto y quizá hasta cínico que aquellas políticas que nos exigen pagar hasta con la libra de carne del drama shakespeareano, sean coincidentes con las doctrinas totalitarias de la "seguridad nacional» que se exportaron a los países en desarrollo y que han inspirado las violaciones de los derechos humanos civiles y políticos más atroces en América latina.

El tema de la deuda externa fue un asunto crucial en la Cumbre de Copenhague, ya que la misma alcanza ahora un billón cuatrocientos mil millones de dólares -el doble de hace una década-, de los cuales quinientos mil millones de dólares corresponden a América latina.

En la sesión inaugural de la Cumbre el representante del Grupo de los 77 que habló en nombre del tercer mundo pidió, "que se den pasos más significativos para la reducción de la deuda, especialmente la cancelación de la deuda de los países donde el peso del endeudamiento obstruye la capacidad de los Estados de suministrar servicios sociales 
adecuados». La deuda de los países más pobres asciende a doscientos treinta mil millones de dólares y concierne a cuarenta y un países de América latina, África y Asia. Los países latinoamericanos destinan en promedio casi la mitad del presupuesto nacional al pago de la deuda, restando recursos que podrían reducir la hambruna de unos doscientos ochenta millones de personas y crear empleo.

Resulta interesante recordar que es por primera vez que los países en desarrollo intentan que se acepte el principio de la condonación de la deuda multilateral, mientras que los países acreedores sostienen, por lo general, que el alivio de la deuda debe hacerse "caso por caso", y las instituciones como el Banco Mundial se oponen a la condonación del débito multilateral.

América latina planteó en la Cumbre Mundial sobre Desarrollo Social la renegociación con equidad de la deuda externa y alertó sobre la necesidad de garantizar la gobernabilidad por el bien de sus "precarias e inestables" democracias. Se dijo que los ajustes neoliberales lograron mejorar las economías pero «ensancharon la brecha entre miseria y opulencia" y sembraron el continente de "bombas de tiempo listas para explotar», como sucedió en Chiapas (México) y como sucederá en otros lugares si no se atienden los graves problemas sociales. Natin Desai, subsecretario general de la ONU para el Desarrollo Sostenible, dijo en Copenhague, "que lo que se acuerde sobre el tema de la deuda externa será uno de los criterios para juzgar si la Cumbre es o no un éxito".

La Unión Europea no ofreció nada concreto, aunque su portavoz, la ministra francesa de Asuntos Sociales, Urbanos y de Salud, Simone Weil, admitió que: "sin un tratamiento adecuado de su endeudamiento los países en desarrollo no podrán poner en marcha las resoluciones que la Cumbre apruebe».

Desgraciadamente, salvo casos aislados, como las condonaciones de la deuda por parte de Dinamarca y Austria, la Cumbre no llegó a plantear soluciones al problema de la deuda externa por falta de consenso de los países acreedores, defraudando las expectativas del tercer mundo.

\section{Principios éticos y jurídicos}

\subsection{Principios éticos}

El Derecho tiene por objeto el implantar un orden justo en la vida social. El Derecho es el medio necesario para alcanzar el fin de la justicia a que toda sociedad aspira. 
La Comisión Pontificia Justicia y Paz, en su documento: Una consideración ética de la deuda internacional, expresa su convicción de que es necesario y urgente una cooperación de todos que permita una solución justa al problema del endeudamiento.

Expresa el documento pontificio que el endeudamiento de los países en desarrollo se sitúa en un amplio contexto de relaciones económicas, políticas y tecnológicas que manifiestan la interdependencia acrecentada de las naciones y la necesidad de una concertación internacional para perseguir objetivos de bien común. Esta inderdependencia, para ser justa, en lugar de conducir al dominio de los más fuertes, al egoísmo de las naciones, a desigualdades e injusticias, debe hacer surgir formas nuevas y ensanchadas de solidaridad, que respeten la igual dignidad de todos los pueblos ${ }^{1}$.

Para salir de la crisis del endeudamiento internacional, la Comisión Pontificia propone que las diferentes partes deben ponerse de acuerdo, a fin de compartir de modo equitativo los esfuerzos del reajuste y los sacrificios necesarios, teniendo en cuenta la prioridad de las necesidades de las poblaciones más indefensas. Los países mejor provistos tienen la responsabilidad de aceptar una más amplia participación.

Concluye esta parte el documento pontificio señalando que para ciertos países la urgencia impone soluciones inmediatas en el marco de una ética de supervivencia. El esfuerzo principal caerá sobre el restablecimiento, dentro de un plazo fijo, de la situación económica y social: reactivación del crecimiento, inversiones productivas, creación de bienes, repartición equitativa. Para evitar el retorno a situaciones de crisis por las variaciones demasiado bruscas del contexto internacional, hay que estudiar y promover una reforma de las instituciones monetarias y financieras.

Este llamado a la solidaridad y a la primacía de la ética, en las relaciones económicas internacionales, desgraciadamente todavía no ha sido escuchado por los gobiernos de los países acreedores, que han mostrado su renuencia a crear el clima internacional que haga viable el pago de la deuda externa.

Es tiempo, nos dice Javier Iguíniz ${ }^{2}$, de impulsar una solución general $y$, en ese sentido, política. Esto no excluye la conveniencia de avances parciales y transitorios en la reducción necesaria de la deuda y de los

COMisión PONTIFicia Justicia y Paz, Una consideración ética de la deuda internacional, Ciudad del Vaticano, p. 10.

2 Iguiniz, Javier, Deuda externa en América latina. Exigencias éticas desde la doctrina social de la Iglesia, Lima, 1995, p. 73. 
pagos, pero esos avances son lentos e insuficientes para atenuar los sufrimientos más masivos de los pueblos pobres. Ello se debe a que dichos logros se realizan en medio de programas de reforma institucional que, inspirados en planteamientos neoliberales, impulsan un creciente desamparo de los débiles al reducir la responsabilidad solidaria del Estado y tratar de configurar un capitalismo cada vez más salvaje. Además, los programas de estabilización antinflacionaria aumentan el desempleo y la miseria, postergando la transmisión de esos beneficios parciales a los que más urgentemente los necesitan. Por eso concluye Iguíniz en que sólo una reducción general y muy grande del servicio de la deuda externa puede resultar beneficiosa para las mayorías latinoamericanas y caribeñas.

Los obispos de los Estados Unidos, en su Carta pastoral sobre "La enseñanza social católica y la economía de los Estados Unidos de América", precisan que los países deudores necesitan, para ajustar las deudas sin perjudicar aún más a los pobres -aunque en última instancia compete al gobierno deudor decidir cómo se han de asignar los costos del ajuste-, tener en cuenta las condiciones de la justicia social internacional al determinar las condiciones de la reprogramación de la deuda y préstamos adicionales. Por ejemplo, no se deben exigir reducciones salariales, no se deben recortar los servicios públicos básicos para los pobres, y se deben tomar medidas para restringir la fuga de capitales ${ }^{3}$.

Concluyen los obispos norteamericanos, este punto, señalando que la creciente deuda externa, constituida en un problema económico que abarca todo el tercer mundo, exige un cambio sistémico para proporcionar alivio inmediato y evitar que vuelva a ocurrir. Las instituciones de Bretton Woods no representan adecuadamente a las naciones del tercer mundo y sus políticas no están afrontando los problemas de aquellas naciones de manera efectiva. Por tanto, es necesario examinar tales politicas y llevar a cabo reformas sustanciales en dichas instituciones y al mismo tiempo hay que enfrentar el problema inmediato de la deuda del tercer mundo, sin pasar por alto el impacto de los déficits presupuestales y comerciales estadounidenses sobre las tasas de interés. Tales elevadas tasas de interés agravan la ya difícil situación de la deuda y succionan los capitales que de otra manera pudieran invertirse en el desarrollo económico de los países del tercer mundo.

\footnotetext{
La enseñanza social católica y la economía de los Estados Unidos de América, Carta pastoral de los obispos de los Estados Unidos de América, Centro de Proyección Cristiana, Lima, 1987, p. 100.
} 
La solución del problema de la deuda externa pasa necesariamente por una ética de sobrevivencia. El derecho a la vida humana y al desarrollo de los pueblos prevalece sobre el derecho patrimonial de los acreedores. Tanto el documento de la Comisión Pontificia, como el de los obispos norteamericanos, señalan que la economía debe ser ante todo humana, vale decir, al servicio de la persona y de la satisfacción de sus necesidades fundamentales.

\subsection{Principios jurídicos}

Las relaciones entre deudores y acreedores han sufrido en el transcurso del tiempo una profunda evolución gracias a la influencia de las ideas humanistas y a los cambios tecnológicos.

En la época primitiva del Derecho romano, el acreedor podía apoderarse de la persona del deudor y reducirlo a la esclavitud. Paulatinamente los deudores han venido alcanzando beneficios. Uno de los más importantes lo constituye la abolición de la prisión por deudas, que subsistió en la mayoría de los países hasta bien entrado el siglo XIX; claro está que ello no significa la impunidad absoluta, pues no incluye a los deudores fraudulentos que han incurrido en el delito de estafa.

Otro beneficio lo constituye el no ser transmisibles las deudas personales, que antes también se heredaban. En la actualidad las deudas patrimoniales sólo gravan la herencia hasta el límite del activo de la misma.

Abolida la ejecución personal se introdujo el principio de la responsabilidad patrimonial, pero en el Derecho positivo de la mayor parte de países no todo el patrimonio del deudor responde de las deudas, y en consecuencia puede ser embargado, para posteriormente ser rematado. Así, por ejemplo, el Código Procesal Civil del Perú, en su artículo 648 precisa cuáles son los bienes inembargables, figurando entre ellos los que resultan indispensables para la sobrevivencia del deudor y el ejercicio de su profesión u oficio, así como las remuneraciones y pensiones cuando no exceden de cinco unidades de referencia procesal. El exceso es embargable hasta en una tercera parte.

De toda esta evolución humanista se deduce que por muy respetables que sean los derechos del acreedor, éstos ocupan en la escala de valores un lugar inferior al derecho a la vida, al trabajo y, en general, al de la satisfacción de las necesidades fundamentales del deudor y de su familia.

En lo que respecta a la cuantía de los intereses, la mayor parte de los códigos penales sancionan la usura, sobre todo cuando se trata del abuso contra personas que se encuentran en estado de necesidad, o de abuso a incapaces o menores. El Código Penal peruano, en su artículo 214 san- 
ciona la usura con pena privativa de la libertad hasta de cuatro años, si el agraviado es persona incapaz o se halla en estado de necesidad.

Trasladada esta estimativa jurídica del ámbito de las personas privadas en el Derecho interno al de las naciones en el Derecho internacional económico, debería significar que el valor de las exportaciones de los países subdesarrollados, que equivalen al salario de las personas, sólo debe servir para el pago de la deuda externa en una proporción no mayor a la que necesita el país para poder atender a las necesidades de sobrevivencia de sus mayorías famélicas, y que es lo que se ha venido en denominar la deuda social. Desgraciadamente este principio fundamental, que éticamente es indiscutible y que jurídicamente ya ha sido consagrado en el Derecho interno de los países civilizados, no rige en las relaciones económicas internacionales, donde la sola ley es la voluntad unilateral de los acreedores.

\section{Fuentes del Derecho internacional: los principios generales del Derecho}

\subsection{Principios generales del Derecho}

Entre las fuentes subsidiarias del Derecho internacional figuran los principios generales del Derecho. En efecto, el artículo 38 del Estatuto de la Corte Internacional de Justicia precisa las normas que utiliza para resolver las controversias, mencionando que además de las convenciones internacionales y la costumbre, que son fuentes principales del Derecho internacional, aplica "los principios generales del Derecho reconocidos por las naciones civilizadas». La enumeración se completa con una referencia a la posibilidad de la Corte de estatuir en equidad, ex aequo et bono, si las partes así lo convinieran.

La fórmula del artículo 38 del Estatuto de la Corte Internacional de Justicia data de 1919, pues ha sido tomada del Estatuto de la Corte Permanente de Justicia Internacional, $y$ ha sido progresivamente precisada por la jurisprudencia y la doctrina.

Sobre lo que se debe entender por "principios generales del Derechom, nos dice Simone Dreyfus ${ }^{4}$ que se trata esencialmente de principios comunes a todos los sistemas de Derecho interno. Una serie de fondos extraídos del Derecho interno de los Estados, común a los Derechos internos y transpuestos al Derecho internacional. Cita como ejemplos:

4 Dreyfus, Simone, Droit des relations internationales, Paris, 1987, p. 144. 
el respeto de los derechos adquiridos, el carácter obligatorio de los compromisos, la obligación de reponer el daño que se ha causado por el hecho de una violación del Derecho internacional, la autoridad de la cosa juzgada. Agrega la autora que ciertos principios generales propios a este Derecho y a las relaciones internacionales pueden igualmente ser considerados como formando parte de los principios generales del Derecho. Los ejemplos citados son: la buena fe en las relaciones internacionales; la continuidad del Estado (en caso de cambio de régimen político); la primacía del Derecho internacional sobre el Derecho interno; el respeto de la independencia y de la soberanía de los Estados; la regla del agotamiento de los recursos internos (antes de acudir a una jurisdicción internacional); el arreglo pacífico de las controversias internacionales. Concluye la autora expresando que estos principios constituyen fuentes del Derecho internacional, jugando un papel complementario en relación con las fuentes principales que son los tratados y la costumbre. Pero lo importante es que se trata de reglas jurídicas, es decir, que estos principios generales tienen un carácter obligatorio, produciendo efectos jurídicos, creando derechos y obligaciones para los sujetos del Derecho internacional. Su violación compromete la responsabilidad del Estado.

La jurisprudencia internacional, en lo que respecta a la supremacía de los principios generales del Derecho sobre los Derechos internos nacionales, tiene una importante ejecutoria en la sentencia arbitral de 19 de enero de 1977 en el caso Texaco-Calasiatic con el gobierno libio ${ }^{5}$, en la que administró justicia como arbitro único René Jean Dupuy.

En el caso sub-litis, las partes contratantes, en base a la autonomía de la voluntad, habían previsto en la cláusula relativa al Derecho aplicable, que, en el supuesto de falta de conformidad entre los principios de la ley libia y los principios del Derecho internacional, se aplicasen subsidiariamente los principios generales del Derecho.

La sentencia arbitral afirma que la expresión «los principios del Derecho internacional es más amplia que la de los principios generales del Derecho, y que deben servir de piedra de toque para la aplicación de la ley libia, puesto que ésta solamente debe ser aplicada si es conforme con aquéllos".

Antonio Belaunde nos dice ${ }^{6}$ que en el Derecho hay dos niveles, a saber: el nivel del Derecho casuístico, o ley en el sentido ordinario de la

\footnotetext{
LALIVE, M. J. F., "Un gran arbitrage petrolier entre un gouvernement et deux societés privées étrangéres", Journal de Droit International, Paris, 1977, t. 104, p. 358.

"Belaunde, Antonio, "Principios generales y la unidad del Derecho", Revista Peruana de Derecho Internacional, n. ${ }^{8} 87$, Lima, 1983, p. 98.
} 
palabra, que también podemos llamar nivel de la lex lata, y el nivel de los principios generales del Derecho.

La lex lata es un sistema que se pretende completo y no contradictorio de normas hipotéticas, casuísticamente formuladas, que cubre en principio todo el campo de aplicación del Derecho y fija las reglas concretas del juego social precisando las consecuencias de los principios generales, en un contexto cultural y nacional dado, de una manera sistemática, coherente y previsible con certeza. El dominio de la lex lata exalta el valor de la seguridad jurídica. Pero este sistema casuístico y sistemático nunca es perfecto, ni está libre de ambigüedades, llegado el caso de contradicciones. Están así los problemas de la oscuridad de la ley, de su vacío o silencio, y, eventualmente, en ciertas circunstancias, de la injusticia manifiesta de su aplicación formal. Estos problemas no pueden dejar de resolverse en la práctica, porque ello equivaldría a una denegatoria de justicia. Por eso, la aplicación formal del sistema casuístico del Derecho, o lex lata, envía al nivel superior de los principios.

Los principios, nos dice Belaunde, son las verdades jurídicas consideradas en sí mismas, cada una independientemente de las demás, y que cumplen una función supletoria cuando la lex lata se revela deficiente.

Se puede observar, nos dice el autor, una cierta dualidad o dialéctica de los principios, cosa que permite distinguir lo que podría llamarse principios del Derecho estricto, como pacta sunt servanda o dura lex sed lex, y los principios que tienen un propósito atenuante o correctivo. Dentro de este criterio, los principios de la equidad tendrían una función rectificadora, morigeradora respecto de los principios del Derecho estricto. Frente al pacta sunt servanda la norma rebus sic stantibus, frente al célebre neminem luedit qui jure sunt utitur-«el que ejerce su derecho no daña»-, tenemos el no menos categórico sumun jus suma injuria, lema sobre el cual se ha construido la moderna figura del abuso del derecho. Pero tan principios generales del Derecho son los llamados del Derecho estricto, como los de la equidad -entendida como parte integral del sistema jurídico de más de una nación-, e invocar a éstos no pretende en forma alguna derogar aquéllos, sino integrarlos todos en la solución justa. Invocar la equidad es apelar al nivel de los principios.

\subsection{Principio del Derecho específicamente invocado en el caso de la deuda externa: la alteración de las circunstancias y la excesiva onerosidad de la prestación o el riesgo imprevisible}

La deuda externa de los países subdesarrollados ha evolucionado de una manera tal que no pudo preverse en el momento en que fue contraída. 
Los mecanismos considerados para asegurar el valor de la deuda en el largo plazo han traído como consecuencia que la deuda haya incrementado sustancialmente su valor, rompiéndose el equilibrio financiero de los contratos que originaron la deuda, dando lugar a la excesiva onerosidad de la contraprestación.

Nos dice Puig Brutau ${ }^{7}$, citando al jurista holandés Meijers, que los efectos obligatorios de los contratos dependen de dos elementos: la voluntad de las partes y la buena fe, agregando que la buena fe exige que el contrato sea cumplido según lo convenido por las partes. Incluso debe mantenerse el cumplimiento de lo acordado en casos en que no siempre puedan estimarse efectivamente previstos. Más adelante, citando a Dahm, agrega que este principio fundamental no debe ser exagerado. La obligación de cumplir el contrato no puede significar un contrasentido. Una serie de acontecimientos extraordinarios que han agitado la vida social de nuestro tiempo han sustraído al individuo aquellas bases de cálculo y previsión que le permitieran hacer frente a las obligaciones asumidas como previstas o, en todo caso, previsibles. En casos excepcionales de esta clase (guerra, crisis en el abastecimiento, inflación y deflación, etc.) el contrato deja de ser un medio justo y dotado de sentido para el intercambio de bienes. Y la parte que en circunstancias como las descritas se aferra tercamente a lo convenido porque la transformación sobrevenida le favorece, a cambio de colocar al deudor mas allá del límite normal del sacrificio, demuestra una grave falta de buena fe; infringe la buena fe en sentido objetivo, esto es, entendida como treu und glauben, la buena fe que es "fidelidad y creencia", necesaria para el buen orden social.

Betti $^{8}$ advierte que la imposibilidad objetiva de la prestación y la excesiva onerosidad se encuentran en la misma línea, y cita al efecto a De Martini, quien dice que la excesiva onerosidad representa un escalón en la escala de la posibilidad de la prestación, más bajo que el de la misma imposibilidad, que es el escalón "último", dando a entender con esto que el tratamiento dado por el Derecho a un caso debe ser similar al que se da al otro, guardando la diferencia que media entre lo imposible y lo excesivamente oneroso.

El problema de la excesiva onerosidad de la prestación, que se manifiesta en la pugna entre la regla pacta sunt servanda, que se inspira en un principio de Derecho estricto, y la cláusula rebus sic stantibus, basada en el principio de equidad, que tiene un propósito atenuante o correctivo, refleja el conflicto, que se presenta en nuestro tiempo con el problema

Puig Brutau, José, Fundamentos de Derecho civih Barcelona, 1954, t. II, v. I, p. 371.

* BeTTI, Emilio, Teoria general de las obligaciones, Madrid, 1969, t. I, p. 210. 
de la deuda externa, entre la seguridad jurídica y la equidad. Por más importante que sea la seguridad jurídica para la vida organizada hay que tener presente que el valor supremo del Derecho es la justicia y no la seguridad.

Nos dice De la Puente y Lavalle ${ }^{9}$ que el contrato es un acuerdo de voluntades para crear obligaciones, las cuales son cumplidas, a su vez, mediante la ejecución de prestaciones. La prestación viene a ser, pues, el contenido del objeto del contrato, que es la obligación. Si nos colocamos en el campo del contrato conmutativo con prestaciones recíprocas, la prestación tiene su explicación, no su causa, en la contraprestación, pues la voluntad de las partes contratantes es que las prestaciones les proporcionen recíprocos beneficios.

Agrega De la Puente y Lavalle que, cuando por razón de un acontecimiento imprevisible para ambos contratantes, o sea, un acontecimiento que ninguno de ellos pensó que podría ocurrir, la prestación se convierte en excesivamente onerosa, entendiendo el concepto excesivo en su acepción de ir más allá de lo lícito o razonable, surge una grosera ruptura del equilibrio contractual que el orden jurídico no debe dejar impune. Y concluye: en la vida, y más aún en el ámbito del Derecho, no puede actuarse en términos férreos, esclavizantes. El Derecho positivo, para ser una manifestación de la justicia, debe estar colmado de equidad y buena fe. Si resulta evidente que el contrato no se hubiera pactado en determinadas condiciones si hubiera podido preverse el acontecimiento que ha causado la excesiva onerosidad de la prestación, va contra la institución misma del contrato, que es y que tiene que ser un acuerdo de voluntades con buena fe, que se permita que la prestación, por la única razón que siempre es posible cumplirla, deba ser exigida a costa de un sacrificio intolerable.

La teoría de la excesiva onerosidad de la prestación o el riesgo imprevisible, exige el cumplimiento de los siguientes requisitos:

1) Ocurrencia de un acontecimiento imprevisible y extraordinario. La deuda externa evolucionó de una manera que no pudo preverse en la fase en que fue contraída. En toda sistematización del Derecho financiero, cuando se trata de créditos a largo plazo, la primera y más importante preocupación del acreedor es que la deuda no se deprecie por el proceso de la inflación. Es por eso que se contemplan procedimientos destinados a asegurar la conservación del valor de una deuda, que dentro del estricto nominalismo del Derecho monetario tendería a depreciarse.

y Puente y Lavalle, Manuel de la, Estudios del contrato privado, Lima, 1983, t. II, p. 139. 
En el caso de la deuda externa sucedió todo lo contrario: la deuda no se ha depreciado, sino que se ha incrementado sustancialmente de una manera que no pudo preverse cuando fue contraída. Y esto a causa de la revaluación del dólar a lo largo del tiempo, unido al alto tipo de interés en los mercados de esa divisa, incorporado a la deuda por la cláusula del tipo de interés móvil.

2) Que ese acontecimiento convierta en excesivamente onerosa una de las prestaciones contractuales, sin llegar a hacerla imposible. En la deuda externa no hay proporción entre la prestación del acreedor, que fue el dinero prestado, y la contraprestación, que es el dinero que tienen que pagar los deudores por los intereses y la amortización de la deuda. Como ya hemos hecho referencia, en una década la deuda se ha duplicado pasando de los setecientos mil millones de dólares a un billón cuatrocientos mil millones de dólares.

En esta última década, nos dice Iguíniz Echeverría ${ }^{10}$, la persistencia e importancia de la deuda externa ha sido puesta en cuestión al registrarse una entrada masiva de capitales durante los primeros años, y al bajar la proporción de las exportaciones que hay que utilizar en el servicio de la deuda externa. En efecto, como es ampliamente conocido, desde 1991 se registra una transferencia positiva de capitales hacia América latina debido a un ingreso neto muy grande que alcanzó su pico en 1992 con 62000 millones de dólares (NN.UU.-CEPAL, Balance preliminar de la economía de América latina y el Caribe, 1993, Santiago de Chile, p. 47); además, la carga de los intereses sigue bajando como proporción de las exportaciones. En 1990 la cifra fue 25,1\%; al año siguiente, 22,6\%; en $1992,19,2 \%$, y en $1993,17,6 \%$. Pero, aún así, el servicio anual sigue siendo elevado y reduce el campo de acción para atender la deuda social latinoamericana. En una reciente apreciación de la CEPAL sobre el tema, se indica que "[....] el coeficiente sigue siendo elevado». Numerosos analistas consideran, por ejemplo, que coeficientes superiores al $10 \%$ constituyen motivo de preocupaciones. Si se exceptúan cinco países latinoamericanos (Costa Rica, Chile, Guatemala, Haití y Paraguay), todos los demás están todavía por encima de esa cifra. Seis países registran coeficientes superiores al 20\%: Nicaragua (116\%), Perú (25\%), Bolivia (23\%), Brasil (20\%), Argentina (22\%) y Honduras (22\%).

El costo social del pago de la deuda externa en la mayor parte de países latinoamericanos resulta insoportable. Adicionalmente al principio de la excesiva onerosidad de la prestación o el riesgo imprevisible, se

10) IguiNiz, Javier, op. cit., p. 94. 
puede incluso hablar de otros principios, como la fuerza mayor y el estado de necesidad que el Derecho reconoce en diversos contextos, como factores excluyentes de responsabilidad y eximentes de obligaciones.

\section{Las opiniones consultivas de la Corte Internacional de Justicia}

La Corte Internacional de Justicia tiene una doble competencia: contenciosa y consultiva. Esta última no es propiamente jurisdiccional, porque no culmina con una decisión obligatoria.

A tenor de lo dispuesto en el artículo 65 del Estatuto de la Corte Internacional de Justicia, las solicitudes consultivas pueden ser referidas a "cualquier cuestión jurídica", pero sólo pueden ser hechas por los órganos de la ONU y por ciertas organizaciones internacionales que formen parte del sistema de las Naciones Unidas.

Como hemos expresado, el problema de la deuda externa es uno de los más álgidos que afecta a la mayoría de los países eufemísticamente denominados "países en vías de desarrollo", y que sin lugar a dudas tiene una base jurídica que resulta imprescindible revisar a la luz de los principios generales del Derecho y a cargo de la Corte Internacional de Justicia, que es el órgano judicial principal del sistema de las Naciones Unidas.

En la XI Conferencia Interparlamentaria Comunidad Europea-América Latina, celebrada en San Pablo del 3 al 7 de mayo de 1993, fue aprobada por unanimidad una moción con la finalidad de que una entidad como la Corte Internacional de Justicia deba ser implicada para puntualizar cuáles son los principios jurídicos preexistentes a los contratos de donde emana la deuda, que deberán regularla de modo tal que dicha deuda no produzca consecuencias de grave violación de los derechos humanos en la mayoría de los países implicados.

Para lograr el pronunciamento de la Corte Internacional de Justicia la moción plantea: «pedir a los Estados miembros que estudien la propuesta de que la Asamblea de las Naciones Unidas solicite que la Corte de $\mathrm{La}$ Haya emita un dictamen que clarifique y estudie el marco ético y jurídico que debe regular los términos de los préstamos internacionales".

Como muy bien precisa el profesor Sandro Schipani ${ }^{11}$, un colegio de jueces puede recoger el impulso que emana de los principios generales

\footnotetext{
1 SCHIPANI, Sandro, "Para un dictamen consultivo de la CIJ sobre el marco ético y jurídico conforme al cual debe ser regulada la deuda externa", en este volumen de DERECHO-PUC.
} 
del Derecho y de las aspiraciones de los pueblos para la realización sustancial de la igualdad. El profesor Schipani agrega que el reconocimiento $\mathrm{y}$ afirmación por parte de un imparcial y competente colegio judicial de los "principios jurídicos" que serían aplicables a la deuda externa, concurriría de un modo altamente constructivo a un planteamiento del problema, más justo y también más digno para todas las partes. El querer un dictamen consultivo de la Corte Internacional de Justicia de La Haya es expresión de una cultura político-jurídica que conoce y confia en la misión del Derecho. Es expresión de una tradición latinoamericana del Derecho internacional que honra las doctrinas de utilidad general para la paz. 